\title{
Potensi Penggunaan Abu Terbang Cangkang Sawit Sebagai Penghilang Arsen dari Limbah Tambang
}

\author{
Rainiyati $^{1^{*}}$, Ahmad Riduan ${ }^{2}$, Sarah Fiebrina Heraningsih ${ }^{3}$ \\ ${ }^{1,2}$ Fakultas Pertanian, Universitas Jambi \\ ${ }^{3}$ Fakultas Teknik, Universitas Jambi \\ *Correspondence email: rainiyati@unja.ac.id
}

\begin{abstract}
Abstrak. Arsen ialah suatu senyawa yang berbahaya yang terakumulasi di alam sebagai akibat dari aktivitas antropogenik, salah satunya berupa penambangan emas. Effluent yang berasal dari sisa penambangan ditinggalkan begitu saja padahal mengandung Arsen yang berada di atas ambang batas yang ditetapkan oleh Pemerintah Republik Indonesia. Tujuan dari penelitian ini ialah menganalisa kemampuan abu terbang cangkang sawit dalam menghilangkan logam Arsen yang berada pada effluent sisa penambangan emas.Teknologi yang diterapkan pada penelitian ini ialah penyerapan dengan jalan pencampuran secara langsung diikuti dengan pendiaman dan penyaringan. Efisiensi penghilangan arsen maksimum yang dicapai pada penelitian ini ialah senilai $81,98 \%$. Semakin lama waktu kontak antara abu terbang cangkang sawit dan sampel limbah maka jumlah Arsen yang berada pada air limbah akan semakin berkurang. Hasil dari penelitian ini menunjukkan bahwa metode penghilangan Arsen dari air limbah menggunakan abu terbang cangkang sawit sangat efektif, mudah untuk diterapkan dan murah dari segi biaya yang dibutuhkan.
\end{abstract}

Kata Kunci: abu terbang cangkang sawit, adsorpsi, effluent tambang emas, limbah sisa pertanian

\begin{abstract}
Arsenic is a dangerous compound that accumulates in nature as a result of anthropogenic activities, one of which is gold mining. Effluent originating from the remaining mining is simply abandoned even though it contains Arsenic which is above the threshold set by the Government of the Republic of Indonesia. The purpose of this study was to analyze the ability of palm shell fly ash to remove arsenic in the residual gold mining effluent. The technology applied in this study was absorption by direct mixing followed by settling and filtering. The maximum arsenic removal efficiency achieved in this study was valued at $81.98 \%$. The longer the contact time between the palm shell fly ash and the waste sample, the less the amount of Arsenic in the waste water will be. The results of this study indicate that the method of removing arsenic from wastewater using palm shell fly ash is very effective, easy to apply and cheap in terms of the cost required.
\end{abstract}

Keywords : palm shell fly ash; adsorption; gold mine effluent; agricultural waste

\section{PENDAHULUAN}

Arsen adalah oksi-anion anorganik, secara kimiawi mirip dengan nitrogen, fosfor, antimon, dan bismut, kadangkadang dianggap sebagai logam berat, meskipun sebenarnya merupakan unsur metaloid (Langsch et al., 2012). Arsen merupakan unsur beracun yang persisten dan bersifat bioakumulatif. Tingkat toksik arsenik tergantung pada keadaan oksidasi dan masalah kesehatan yang disebabkan oleh organisme hidup yang rentan terhadap unsur metaloid, termasuk didalamnya dapat menyebabkan melanosis, kanker, keratosis, kerusakan otak hingga gangguan jantung (Shankar, Shanker, \& Shikha, 2014; WHO, 2018).

Emisi arsen ke atmosfer berasal dari berbagai sumber antropogenik seperti diantaranya pembakaran bahan bakar fosil, pertambangan, produksi pupuk, peleburan, pengolahan semikonduktor, produksi obat kemoterapi, dan industri kaca (Rahman \& Singh, 2019). Untuk mengurangi bahaya arsen dari air terhadap kesehatan manusia dan lingkungan, banyak peneliti telah mengembangkan sejumlah besar teknologi penghilangan arsen dari air diantaranya mencakup mencakup oksidasi katalitik, adsorpsi, oksidasi lanjutan, oksidasi tradisional, koagulasi-presipitasi, filtrasi, pertukaran ion, reverse osmosis dan lain-lain (Basu, Saha, Saha, Ghosh, \& Saha, 2014; Dias \& Fontes, 2020; Rodríguez-Romero et al., 2020; Wang, Liu, Zhang, Zou, \& Anthony, 2018).

Adsorpsi permukaan dan pertukaran anion dianggap sebagai proses fisikokimia yang paling efektif untuk menghilangkan oksi-anion berbahaya, seperti Arsen, dari air yang terkontaminasi bahkan dalam konsentrasi yang kecil (Toledo, Bellato, Pessoa, \& Ferreira, 2013). Adsorben yang berasal dari biomassa, seperti yang berasal dari limbah pertanian merupakan salah satu adsorben alternatif yang digunakan untuk menghilangkan kandungan arsen dari air limbah (Ungureanu, Santos, Boaventura, \& Botelho, 2015). Selain karena keanekaragamannya, biodegradabilitasnya, dan kelimpahannya, adsorben yang dihasilkan dari biomassa sangat diminati juga karena dapat menyerap kation dan molekul organik (Huff, Kumar, \& Lee, 2014; Mendoza-Castillo, Reynel-Ávila, Bonilla-Petriciolet, Pastore, \& di Bitonto, 2019).

Salah satu adsorben dari limbah pertanian yang potensial digunakan sebagai penghilang logam arsen pada air limbah ialah adsorben yang berasal dari limbah kelapa sawit karena kaya akan silika. Meskipun belum banyak penelitian mengenai hal tersebut, faktanya biomassa pertanian kelapa sawit merupakan sumber bahan adsorben berbasis silika terbarukan yang menjanjikan, terutama untuk negara-negara penghasil minyak sawit seperti Malaysia 
dan Indonesia (Yusof et al., 2020). Sekitar 4,5 juta ton limbah padat kelapa sawit, khususnya abu terbang cangkang sawit diproduksi per tahun, data ini menunjukkan potensi abu terbang cangkang sawit sebagai bahan baku adsorben untuk menghilangkan kandungan Arsen pada air limbah (Yusof et al., 2020). Penggunaan abu terbang cangkang sawit cukup layak dan juga menarik untuk dilakukan karena abu terbang cangkang sawit yang tidak diolah (raw) mengandung $68 \% \mathrm{SiO}_{2}$ (Tai et al., 2018). Selain itu, abu terbang cangkang sawit merupakan adsorben yang murah (Yanyan et al., 2018), terbarukan, dan menunjukkan pelepasan karbon dioksida yang rendah (Elias et al., 2018).

Abu terbang cangkang sawit juga dikenal memiliki sifat penyerapan yang baik terhadap polutan dari lingkungan, sehingga menjadi salah satu solusi yang tepat untuk mengatasi keberadaan arsen dalam air limbah secara efektif dengan kapasitas penyerapan yang wajar (Samad, Salleh, Zahari, \& Yussof, 2019; Yusof et al., 2020). Penggunaan abu terbang cangkang sawit sebagai daur ulang produk sampingan pertanian ini secara tidak langsung dapat menyelesaikan masalah lingkungan yang berkaitan dengan masalah sistem manajemen pembuangan (Ahmad, Hameed, \& Aziz, 2007; Samad et al., 2019). Bersdasarkan hal tersebut, penelitian ini bertujuan untuk menghilangkan kandungan Arsen dari air limbah tambang emas menggunakan abu terbang cangkang sawit tanpa pengolahan (raw) dengan menggunakan variasi waktu kontak sebagai standar variabel penelitian.

\section{METODE}

Bahan baku yang digunakan pada penelitian ini ialah abu terbang cangkang sawit sebagai bahan penyerap arsen dari air limbah. Abu terbang cangkang sawit yang digunakan pada penelitian ini dihasilkan sebagai limbah dari pembakaran cangkang sawit pada boiler dari suatu perusahaan karet yang ada di Provinsi Jambi. Sampel limbah emas yang digunakan sebagai media yang diuji penurunan kandungan logam Arsen nya pada penelitian ini diambil dari effluent sisa penambangan emas dari salah satu lubang galian ilegal yang berlokasi di Kabupaten Merangin, Propinsi Jambi. Penelitian dilakukan dalam skala laboratorium dan teknologi yang digunakan ialah penyerapan dengan jalan pencampuran secara langsung diikuti dengan pendiaman dan penyaringan. Air bersih yang telah dilakukan proses adsorpsi diuji menggunakan Inductively Coupled Plasma (ICP) mass spectrometer unuk mengukur jumlah logam Arsen yang terkandung dalam air olahan.

Pengujian sampel dilakukan menggunakan 1 liter sampel effluent limbah emas yang dicampurkan dengan abu terbang cangkang sawit dengan pengadukan lambat selama 15 menit, kemudian sampel didiamkan dengan variasi waktu 30, 60 hingga 90 menit sebelum kemudian di filtrasi untuk memisahkan abu terbang cangkang sawit dan air olahan. Proses ini dilakukan tiga kali perulangan dengan melakukan variasi terhadap waktu kontak. Tahapan akhir dari penelitian ini ialah mengukur jumlah Arsen pada air olahan dengan menggunakan Inductively Coupled Plasma (ICP) mass spectrometer dan mengukur nilai efisiensi penghilangan arsen (\%) menggunakan persamaan dibawah ini (Kumar, Kadirvelu, Mishra, Rajagopal, \& Nagar, 2008; Yu et al., 2019) :

$$
\text { Efisiensi Penghilangan Arsen }(\%)=\frac{\left(c_{o}-c_{e}\right)}{c_{o}} \times 100
$$

Dimana:

$\mathrm{C}_{\mathrm{o}}(\mathrm{mg} / \mathrm{L})$ adalah konsentrasi awal Arsen dalam solution

$\mathrm{C}_{\mathrm{e}}(\mathrm{mg} / \mathrm{L})$ adalah konsenrasi akhir Arsen dalam solution

\section{HASIL DAN PEMBAHASAN}

Nilai dari pengurangan kandungan Arsen menggunakan abu terbang cangkang sawit dapat dilihat pada Tabel 1. Kandungan awal Arsen pada effluent limbah tambang emas seperti yang ditampilkan pada Tabel 1 menunjukkan nilai diatas yang disarankan oleh Pemerintah Republik Indonesia dalam PP 82 Tahun 2001 untuk kriteria mutu air kelas satu, yaitu diatas $0,05 \mathrm{mg} / \mathrm{L}$ (Indonesia, 2001). Setiap nilai data jumlah Arsen pada solution menunjukkan nilai ratarata dari 3 kali test yang diuji Inductively Coupled Plasma (ICP) mass spectrofotometry. Menggunakan persamaan (1), efisiensi penghilangan arsen (\%) dari Arsen telah dihitung dan ditampilkan pada Tabel 1. Berdasarkan data yang telah ditampilkan pada Tabel 1 (yang menunjukkan nilai efisiensi adsorpsi dan waktu kontak antara abu terbang cangkang sawit dan effluent limbah emas) maka dibuatlah sebuah plot seperti grafik yang ditunjukkan pada Gambar 1 yang menunjukkan nilai perbandingan kurva eksponensial (Persamaan 2) dan koefisien $R^{2}$ yang sebanding dengan 0,9984 .

Tabel 1. Data Penelitian

\begin{tabular}{ccc}
\hline Waktu Kontak & As pada Solution $(\mathrm{mg} / \mathrm{L})$ & Efisiensi Penghilangan Arsen $(\%)$ \\
\hline 0 & 0,0555 & - \\
30 & 0,0280 & 49,54 \\
60 & 0,0195 & 64,86 \\
90 & 0,01 & 81,98 \\
\hline
\end{tabular}




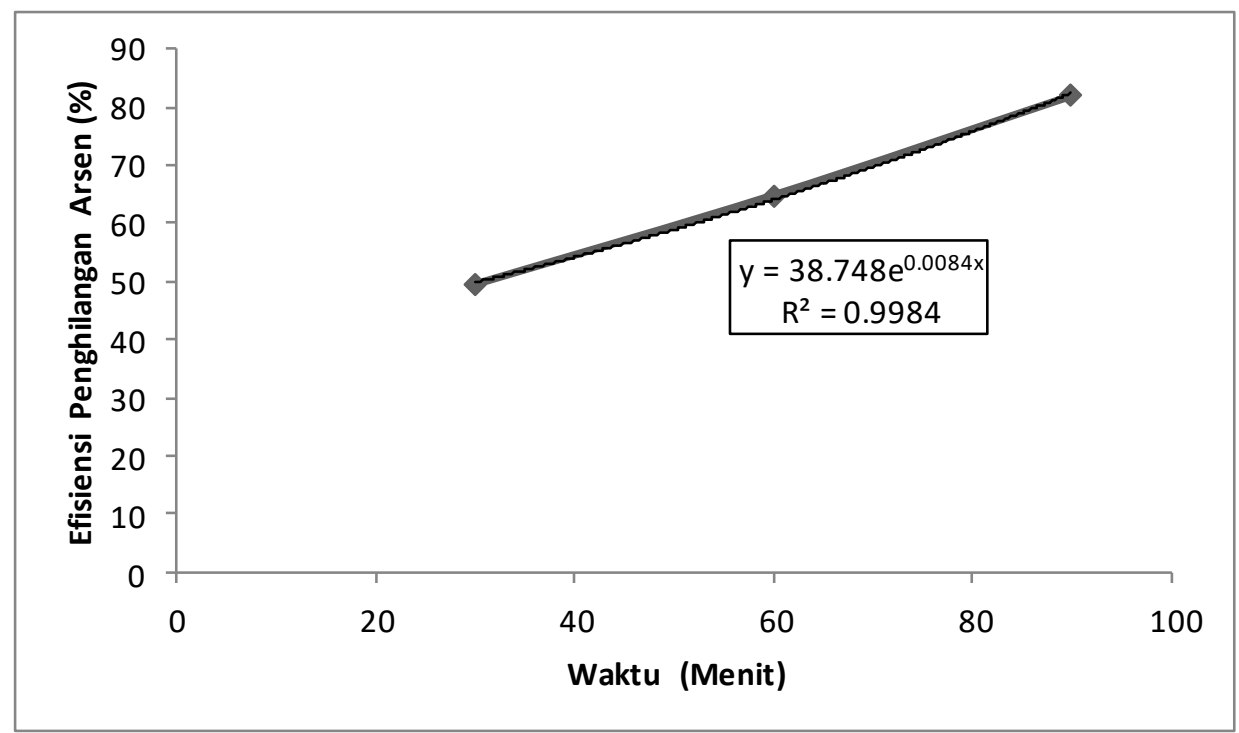

Gambar 1. Efisiensi Penghilangan Arsen (\%) vs. Waktu Pendiaman

$\%$ As $=38,748 \mathrm{e}^{0,0084(\mathrm{~T})}$ diperlukan.

Dimana $\%$ As $=$ estimasi nilai efisiensi penghilangan arsen $(\%)$ dan $\mathrm{T}=$ total waktu pendiaman yang

Sehingga, dengan menggunakan prediksi dari Persamaan 2 untuk menghitung jumlah waktu kontak yang dibutuhkan untuk mencapai efisiensi penghilangan Arsen pada effluent limbah emas hingga mencapai 100\% dibutuhkan waktu 112,87 menit, yang berarti butuh waktu 22,87 menit untuk menyempurnakan proses penghilangan arsen dari air limbah.

\section{SIMPULAN}

Penambangan emas secara ilegal menghasilkan effluent yang mengandung logam Arsen yang jumlahnya di atas ambang batas yang ditetapkan Pemerintah Republik Indonesia. Oleh sebab itu, diperlukan suatu metode untuk meminimalisir jumlah polutan Arsen yang ada pada air limbah. Salah satu cara penanggulangan Arsen ialah melalui jalan penyerapan yang telah terbukti mampu mengurangi jumlah polutan secara efektif. Bahan yang disarankan untuk digunakan dalam proses ini ialah yang berasal dari biomassa, salah satu nya yang berasal dari limbah sisa pertanian karena memiliki harga yang murah dan jumlahnya melimpah di alam. Berdasarkan penelitian yang telah dilakukan, abu terbang cangkang sawit mampu mengurangi jumlah Arsen dengan efisiensi penghilangan arsen (\%) hingga 81,98 $\%$ dengan nilai akhir Arsen yang berada pada air limbah sebesar $0,01 \mathrm{mg} / \mathrm{L}$ (dibawah standar yang ditetapkan Pemerintah Republik Indonesia yaitu 0,05 mg/L). Semakin lama waktu pendiaman antara abu terbang cangkang sawit dan sampel limbah maka jumlah akhir kandungan Arsen yang berada pada air limbah akan semakin kecil. Hasil evaluasi yang dilakukan dari penelitian ini menunjukkan bahwa abu terbang cangkang sawit merupakan salah satu alternatif untuk mengurangi kandungan Arsen pada air limbah secara efektif, murah dan mudah untuk diaplikasikan.

\section{DAFTAR PUSTAKA}

Ahmad, A. A., Hameed, B. H., \& Aziz, N. (2007). Adsorption of direct dye on palm ash: Kinetic and equilibrium modeling. Journal of Hazardous Materials, 141(1), 70-76. https://doi.org/10.1016/j.jhazmat.2006.06.094

Basu, A., Saha, D., Saha, R., Ghosh, T., \& Saha, B. (2014). A review on sources, toxicity and remediation technologies for removing arsenic from drinking water. Research on Chemical Intermediates, 40(2), 447-485. https://doi.org/10.1007/s11164-012-1000-4

Dias, A. C., \& Fontes, M. P. F. (2020). Arsenic (V) removal from water using hydrotalcites as adsorbents: A critical review. Applied Clay Science, 191(January), 105615. https://doi.org/10.1016/j.clay.2020.105615

Elias, N., Chandren, S., Razak, F. I. A., Jamalis, J., Widodo, N., \& Wahab, R. A. (2018). Characterization, optimization and stability studies on Candida rugosa lipase supported on nanocellulose reinforced chitosan prepared from oil palm biomass. International Journal of Biological Macromolecules, 114, 306-316. https://doi.org/10.1016/j.ijbiomac.2018.03.095

Huff, M. D., Kumar, S., \& Lee, J. W. (2014). Comparative analysis of pinewood, peanut shell, and bamboo biomass derived biochars produced via hydrothermal conversion and pyrolysis. Journal of Environmental Management, 146, 303-308. https://doi.org/10.1016/j.jenvman.2014.07.016 
Indonesia, P. R. (2001). Baku Mutu Air. In PERATURAN PEMERINTAH REPUBLIK INDONESIA NOMOR 82 TAHUN 2001 TENTANG PENGELOLAAN KUALITAS AIR DAN PENGENDALIAN PENCEMARAN AIR.

Kumar, A., Kadirvelu, K., Mishra, G. K., Rajagopal, C., \& Nagar, P. N. (2008). Adsorptive removal of heavy metals from aqueous solution by treated sawdust ( Acacia arabica ). 150, 604-611. https://doi.org/10.1016/j.jhazmat.2007.05.030

Langsch, J. E., Costa, M., Moore, L., Morais, P., Bellezza, A., \& Falcão, S. (2012). New technology for arsenic removal from mining effluents. Journal of Materials Research and Technology, 1(3), 178-181. https://doi.org/10.1016/S2238-7854(12)70030-3

Mendoza-Castillo, D. I., Reynel-Ávila, H. E., Bonilla-Petriciolet, A., Pastore, C., \& di Bitonto, L. (2019). Avocado seeds valorization as adsorbents of priority pollutants from water. Bulgarian Chemical Communications, 51, 124-127. https://doi.org/10.34049/bcc.51.B.009

Rahman, Z., \& Singh, V. P. (2019). The relative impact of toxic heavy metals (THMs) (arsenic (As), cadmium (Cd), chromium $(\mathrm{Cr})(\mathrm{VI})$, mercury $(\mathrm{Hg})$, and lead $(\mathrm{Pb}))$ on the total environment: an overview. Environmental Monitoring and Assessment, 191(7). https://doi.org/10.1007/s10661-019-7528-7

Rodríguez-Romero, J. A., Mendoza-Castillo, D. I., Reynel-Ávila, H. E., de Haro-Del Rio, D. A., González-Rodríguez, L. M., Bonilla-Petriciolet, A., ... Camacho-Aguilar, K. I. (2020). Preparation of a new adsorbent for the removal of arsenic and its simulation with artificial neural network-based adsorption models. Journal of Environmental Chemical Engineering, 8(4), 103928. https://doi.org/10.1016/j.jece.2020.103928

Samad, K. A., Salleh, I. S. M., Zahari, M. A. K. M., \& Yussof, H. W. (2019). Batch study on the removal of mercury (II) ion from industrial wastewater using activated palm oil fuel ash. Materials Today: Proceedings, 17, 11261132. https://doi.org/10.1016/j.matpr.2019.06.536

Shankar, S., Shanker, U., \& Shikha. (2014). Arsenic contamination of groundwater: A review of sources, prevalence, health risks, and strategies for mitigation. Scientific World Journal, 2014. https://doi.org/10.1155/2014/304524

Tai, Z. S., Othman, M. H. D., Hubadillah, S. K., Ismail, A. F., Rahman, M. A., Jaafar, J., ... Abd Aziz, M. H. (2018). Low cost palm oil fuel ash based ceramic membranes for oily water separation. Malaysian Journal of Fundamental and Applied Sciences, 14(4), 419-424. https://doi.org/10.11113/mjfas.v14n4.1218

Toledo, T. V., Bellato, C. R., Pessoa, K. D., \& Ferreira, M. P. (2013). Remoção De Cromo (Vi) De Soluções Aquosas Utilizando O Compósito Magnético Calcinado Hidrotalcita- Óxido De Ferro: Estudo Cinético E De Equilíbrio Termodinâmico. Quimica Nova, 36(3), 419-425. https://doi.org/10.1590/S0100-40422013000300012

Ungureanu, G., Santos, S., Boaventura, R., \& Botelho, C. (2015). Arsenic and antimony in water and wastewater: Overview of removal techniques with special reference to latest advances in adsorption. Journal of Environmental Management, 151, 326-342. https://doi.org/10.1016/j.jenvman.2014.12.051

Wang, C., Liu, H., Zhang, Y., Zou, C., \& Anthony, E. J. (2018). Review of arsenic behavior during coal combustion: Volatilization, transformation, emission and removal technologies. Progress in Energy and Combustion Science, 68, 1-28. https://doi.org/10.1016/j.pecs.2018.04.001

WHO. (2018). Arsenic. Retrieved from World Health Organization website: https://www.who.int/newsroom/\%0Afact-sheets/detail/arsenic

Yanyan, L., Kurniawan, T. A., Zhu, M., Ouyang, T., Avtar, R., Dzarfan Othman, M. H., ... Albadarin, A. B. (2018). Removal of acetaminophen from synthetic wastewater in a fixed-bed column adsorption using low-cost coconut shell waste pretreated with $\mathrm{NaOH}, \mathrm{HNO}$, ozone, and/or chitosan. Journal of Environmental Management, 226(August), 365-376. https://doi.org/10.1016/j.jenvman.2018.08.032

Yu, X., Wei, Y., Liu, C., Ma, J., Liu, H., Wei, S., ... Luo, S. (2019). Chemosphere Ultrafast and deep removal of arsenic in high-concentration wastewater: A superior bulk adsorbent of porous $\mathrm{Fe} 2 \mathrm{O} 3$ nanocubes$\begin{array}{lllll}\text { impregnated } \quad \text { graphene } & \text { aerogel. } & \text { Chemosphere, 262, }\end{array}$ https://doi.org/10.1016/j.chemosphere.2019.01.130

Yusof, M. S. M., Othman, M. H. D., Wahab, R. A., Jumbri, K., Razak, F. I. A., Kurniawan, T. A., ... Ismail, A. F. (2020). Arsenic adsorption mechanism on palm oil fuel ash (POFA) powder suspension. Journal of Hazardous Materials, 383(January 2019), 121214. https://doi.org/10.1016/j.jhazmat.2019.121214 